\title{
Iniciação científica nos cursos de licenciatura e contribuições para a formação de professores
}

\author{
Undergraduate research project in licentiate courses \\ and its contributions to teacher training
}

Iniciación científica para cursos de graduación y contribuciones a la formación del professorado

Renata Cristina Oliveira Barrichelo CunHa (iDa

ANDREZA BARBOSA (iD)

THIAGO ANTUNES-SOUZA

\section{Resumo}

Considerando que a participação em projetos de Iniciação Científica (IC) se constitui como uma oportunidade privilegiada de inserção de estudantes de licenciatura na pesquisa, este artigo busca analisar as contribuições da IC para a formação inicial de professores e sistematiza o estado do conhecimento a respeito do tema consultando a Biblioteca Digital de Teses e Dissertações (BDTD), Banco de Dissertações e Teses da Coordenação de Aperfeiçoamento de Pessoal de Nível Superior (Capes) e Scientific Electronic Library Online (SciELO) no período 2000-2020. Os resultados evidenciaram aspectos relacionados às contribuições da IC para a formação acadêmica e científica dos bolsistas, para a permanência no ensino superior e para o exercício da docência. Do ponto de vista da formação e exercício da docência, a experiência da IC contribui com a construção de um olhar e postura investigativas diante da complexidade da prática pedagógica, deslocando o professor do lugar de "consumidor" de ideias e teorias para um lugar de "construtor" de conhecimentos. Do mesmo modo, o professor deixa de se reconhecer como "transmissor" de conhecimentos e reconhece seus alunos como "construtores" de conhecimentos. A IC na licenciatura pode ser considerada como

\footnotetext{
a Centro Universitário Salesiano de São Paulo, São Paulo, SP, Brasil. Doutora em Educação, email: renata_bcunha@yahoo.com.br

b Universidade de Sorocaba, Sorocaba, SP, Brasil. Doutora em Educação Escolar, e-mail: andrezab27@gmail.com

c Universidade Federal de São Paulo, São Paulo, SP, Brasil. Doutor em Educação, e-mail: tasouza@unifesp.br
} 
experiência formativa na medida em que admite os conhecimentos da sala de aula e os saberes dos professores como problemáticos e o percurso investigativo como possibilidade de elaboração e reelaboração desses conhecimentos e saberes.

Palavras-chave: Formação de professores. Iniciação científica. Iniciação à pesquisa.

\begin{abstract}
Taking into consideration that the participation in undergraduate research projects (IC) constitutes a prestigious opportunity for the inclusion of students from licentiate courses in research, the aim of this article is to analyze the contributions of the IC to the teachers' initial training and systematize the state of knowledge concerning the theme by consulting the databases Biblioteca Digital de Teses e Dissertações (BDTD) [Digital Library of Theses and Dissertations], Banco de Dissertações e Teses [Research Bank of Dissertations and Theses] da Coordenação de Aperfeiçoamento de Pessoal de Nível Superior (Capes) [Coordination for the Improvement of Higher Education Personnel] and Scientific Electronic Library Online (SCIELO), between 2000 and 2020. The results showed aspects that are related to the contributions of the IC to the scholarship holders' academic and scientific formation, the permanence in higher education and the teaching practice. From the point of view of teacher training and teaching practice, the IC's experience contributes to the construction of an investigative look and stance in face of the complexity of the pedagogical practice, that moves the teacher from a "consumer" of ideas and theories to a "producer" of knowledge. Similarly, the teacher refrains from recognizing himself as a "transmitter" of knowledge and recognizes his students as "builders" of knowledge. The IC in licentiate courses can be considered a formative experience as it understands the knowledge acquired in the classroom and the teachers' expertise as problematic and the investigative pathway as a possibility for the elaboration and re-elaboration on this knowledge and expertise.
\end{abstract}

Keywords: Teacher training. Undergraduate research project. Introduction to research.

\title{
Resumen
}

Considerando que la participación en proyectos de Iniciación Científica (IC) se constituye como una privilegiada oportunidad de inserción de estudiantes de licenciatura en la investigación, este artículo busca hacer un análisis de las contribuciones de la IC para la inicial formación de profesores y sistematiza el estado del conocimiento a respeto del tema consultando la Biblioteca Digital de Teses e Dissertações (BDTD), Banco de Dissertações e Teses da Coordenação de Aperfeiçoamento de Pessoal de Nível Superior (Capes) y Scientific Electronic Library Online (SciELO) en el período 2000-2020. Los resultados evidenciaron aspectos relacionados a las contribuciones de la IC para la formación académica y científica de los becados, para la permanencia en la enseñanza superior y para el ejercicio de la docencia. Del punto de vista de la formación y ejercicio de la docencia, la experiencia de la IC contribuye con la construcción de una mirada y postura de investigación sobre la complexidad de la práctica pedagógica, cambiando el profesor de la posición del "consumidor" de ideas y teorías para la de "productor" de conocimientos. Así también, el profesor deja de reconocerse como "transmisor" de conocimientos y reconoce a sus alumnos como "constructores" de conocimientos. La IC en la licenciatura puede ser considerada como práctica formativa a la medida que admite que los conocimientos del aula y los saberes de 
los profesores como problemáticos y la ruta investigativa como posibilidad de elaboración y reelaboración de esos conocimientos y saberes.

Palabras clave: Formación de profesores. Iniciación científica. Iniciación a la investigación.

\section{Introdução}

Considerando que a pesquisa constitui elemento importante na formação inicial dos professores (CUNHA, 2006; MASSI; QUEIROZ, 2010; ANDRÉ, 2012; LÜDKE, 2012; entre outros) e que a principal forma de inserção de estudantes de licenciatura na pesquisa se dá por meio da participação em projetos de Iniciação Científica (IC), esse artigo busca analisar as contribuições da IC na formação inicial de professores. Para dar conta do proposto, recorre-se à revisão de literatura junto a artigos científicos, dissertações e teses produzidos nos últimos 20 anos (2000-2020) que se dedicaram ao estudo dessa temática, compondo um estado do conhecimento.

O interesse pelas implicações da experiência de IC nas licenciaturas se justifica pelo fato de que, como destacado por Gatti, Barretto e André (2011, p. 89),

a formação inicial de professores tem importância ímpar, uma vez que cria as bases sobre as quais esse profissional vem a ter condições de exercer a atividade educativa na escola com as crianças e os jovens que aí adentram, como também, as bases de sua profissionalidade e da constituição de sua profissionalização.

Partimos do pressuposto de que uma referência fundamental para a formação e constituição da profissionalidade docente é a pesquisa. Não sendo uma atividade técnica que obedece à lógica das especialidades, à docência como ação complexa (CUNHA, 2004; SOARES; CUNHA, 2010), precisa ser permanentemente problematizada nos cursos de licenciatura. Nesse sentido, Cunha (2006) destaca a importância da atividade de pesquisa como instrumento que auxilie os professores na compreensão de seu contexto e realidade para tomada de decisões.

Gatti e Nunes (2009) e Lüdke (2012) também reconhecem a importância da formação que contemple a pesquisa como princípio formativo para a atuação de professores que mais tarde vão estar inseridos na educação básica, mas destacam dificuldades relacionadas à organização curricular dos cursos de licenciatura que, além de não terem superado a dicotomia teoria-prática, oferecem atividades/disciplinas que discutem questões ligadas à pesquisa somente para a elaboração dos trabalhos de conclusão 
de curso. As atividades de pesquisa, segundo Gatti e Nunes (2009), costumam estar associadas à pós-graduação, reforçando a ordem hierárquica da academia universitária que reconhece e valoriza a pós-graduação como espaço de produção de conhecimentos pela pesquisa e a formação de professores nas licenciaturas como campo de aplicação.

Nesse sentido, a IC se apresenta, muitas vezes, como único espaço de contato do futuro professor com a pesquisa ao longo do curso de licenciatura. A pesquisa de IC, supomos, pode estimular e favorecer ações de pesquisa da própria prática durante seu trabalho na escola, colaborando com a formação de uma postura investigativa.

A ideia de investigação como postura, proposta por Cochran-Smith e Lytle (1999, 2009), implica a formação de um tipo de pensamento que envolve um processo contínuo de problematizar o cotidiano; questionar as formas como conhecimento e a prática são construídos, avaliados e empregados; desafiar as próprias suposições; identificar questões importantes da prática de sala de aula, propondo problemas e estudando os próprios estudantes, salas de aula e escolas.

O financiamento das bolsas de IC no Brasil é feito principalmente pelo Conselho Nacional de Desenvolvimento Científico e Tecnológico (CNPq), criado em 1951 para atender à necessidade de institucionalizar as ações de incentivo e fomento à pesquisa e valorizar a importância estratégica da ciência para o desenvolvimento do país.

O CNPq financia as atividades de IC desde 1963, mas em 1988 criou o Programa Institucional de Bolsas de Iniciação Científica (PIBIC), atualmente regulamentado pela RN 017/2006 (BRASIL, 2006), que estabelece as normas gerais e específicas para as modalidades de bolsas por quota no País. As bolsas de IC, a partir do PIBIC, são repassadas às instituições por meio de quotas proporcionais ao número de pesquisadores do CNPq em seus quadros, bem como ao número, nível e dimensão de seus programas de pós-graduação.

Em termos de amplitude do PIBIC, apesar de fomentar a maior parte das pesquisas de IC no país, se considerarmos, de acordo com Sinopse Estatística da Educação Superior 2018 publicada pelo Instituto Nacional de Estudos e Pesquisas Educacionais Anísio Teixeira (2019), que em 2018 havia 6.394 .244 alunos matriculados nos cursos de graduação presenciais, o número de bolsas PIBIC é pouco expressivo, mesmo considerando as contrapartidas institucionais. Consulta feita no Mapa de Investimentos do CNPq (CNPq, 2019a) informa a concessão de 25.383 
bolsas para 369 instituições no país em 2019-2020. Houve uma diminuição de bolsas em relação a 2015, quando foram oferecidas 27.717 bolsas de IC (CNPq, 2019b).

No que tange aos seus fins, o PIBIC objetiva, entre outros aspectos, proporcionar ao bolsista, orientado por pesquisador qualificado, "a aprendizagem de técnicas e métodos de pesquisa, bem como estimular o desenvolvimento do pensar cientificamente e da criatividade, decorrentes das condições criadas pelo confronto direto com os problemas de pesquisa" (BRASIL, 2006).

Muito embora o PIBIC tenha como foco a formação de recursos humanos para a pós-graduação, entre seus objetivos gerais pode-se destacar a preocupação com a contribuição para a formação de outras atividades profissionais (BRASIL, 2006). Nessa perspectiva admite-se que a pesquisa é um componente fundamental para a formação acadêmica e profissional dos licenciandos e para a docência na educação básica.

Massi e Queiroz (2010), em levantamento anterior, inventariaram as produções acadêmicas publicadas sobre a IC no país no período de 1983-2007 e identificaram poucos estudos a respeito, apesar da disseminação das atividades de IC nas universidades. Foram localizadas, no período destacado, 11 dissertações de mestrado, 6 teses de doutorado e 4 artigos completos publicados em revistas nacionais, os quais tematizavam a IC em cursos de graduação de modo geral.

A sistematização das leituras e análises permitiu às autoras identificar que, de modo geral, o envolvimento dos alunos de graduação nas atividades de IC permite superar a dicotomia entre graduação e pós-graduação, ensino e pesquisa e teoria e prática. A graduação deixa de ser vista como espaço de reprodução de conhecimentos e assume sua dimensão de produção de conhecimentos.

A IC contribui, segundo Massi e Queiroz (2010), com a melhora do desempenho dos alunos, uma vez que eles têm a oportunidade de desenvolver outros procedimentos e atitudes frente ao estudo; favorece o desenvolvimento pessoal, ao estimular o pensamento crítico, a autonomia, a construção da própria opinião e uma autoimagem positiva como aluno; desmistifica a ciência, possibilitando a compreensão do processo de construção do conhecimento científico e do papel do cientista; e amplia a socialização profissional ao proporcionar a oportunidade de inserção em grupos de alunos, orientadores, colaboradores etc. 
Tendo em vista a importância da IC para a formação geral dos estudantes de graduação, interessa-nos aqui explorar as contribuições da IC para a formação de professores nos cursos de licenciaturas, grupo de alunos que ainda não foi objeto de investigação dos autores consultados nesse trabalho.

\section{Levantamento da produção acadêmica}

De caráter bibliográfico, esta pesquisa pode ser caracterizada como estado do conhecimento que, segundo Ferreira (2002), apresenta o desafio de inventariar e descrever a produção acadêmica sobre um determinado tema, identificando os aspectos e dimensões que caracterizam o conjunto de trabalhos.

A relevância deste tipo de pesquisa, segundo Soares (1989), justifica-se pela possibilidade de discutir perspectivas e identificar lacunas a partir da organização da produção acadêmica.

O levantamento da produção acadêmica foi feito considerando-se o período de 2000-2020 em três bases de dados: Biblioteca Digital de Teses e Dissertações (BDTD), Banco de Dissertações e Teses da Coordenação de Aperfeiçoamento de Pessoal de Nível Superior (Capes) e Scientific Electronic Library Online (SciELO).

$\mathrm{Na}$ BDTD optamos pelo termo de busca "iniciação científica" nas categorias "assunto" e "título". Excluindo-se as repetições, foram encontrados 41 trabalhos. O Banco de Dissertações e Teses da Capes não tem um sistema de busca avançada que permita o uso do termo "iniciação científica" associado ao assunto ou título do trabalho. O emprego do termo "iniciação científica” incorporou aos resultados um conjunto de trabalhos que não tinha nenhuma relação com os objetivos da pesquisa. Foi necessário substituir esse termo por "PIBIC" para melhor delimitação da busca. Com o termo "PIBIC" foram identificados 96 trabalhos, dos quais 39 correspondiam à área de avaliação em Educação. Circunscrevemos nossa atenção a esse conjunto de pesquisas.

Por fim, na consulta ao SciELO recorremos ao termo "iniciação científica" nos campos assunto e título, sendo identificados 20 registros.

Sendo o objetivo do presente artigo analisar as contribuições da IC na formação docente inicial, o critério para escolha dos trabalhos e análise foi selecionar pesquisas que exploravam especificamente a iniciação científica em cursos de 
formação de professores, em qualquer aspecto. Deste modo, após leitura atenta dos resumos das dissertações, teses e artigos identificados nas bases de dados, selecionamos 11 trabalhos, conforme tabela a seguir:

Tabela 1 - Produção acadêmica analisada

\begin{tabular}{|c|c|c|c|c|}
\hline Ano & Autor & Título & Nível & Fonte \\
\hline 2003 & $\begin{array}{l}\text { MELO, Gilberto } \\
\text { Francisco Alves de }\end{array}$ & $\begin{array}{l}\text { A formação inicial e a iniciação científica: investigar e produzir } \\
\text { saberes docentes no ensino de álgebra elementar }\end{array}$ & $\mathrm{D}$ & BDTD \\
\hline 2007 & $\begin{array}{l}\text { KIRSCH, Deise } \\
\text { Becker }\end{array}$ & $\begin{array}{l}\text { A iniciação científica na formação inicial de professores: } \\
\text { repercussões no processo formativo de egressas do } \\
\text { curso de pedagogia }\end{array}$ & $M$ & CAPES \\
\hline 2008 & $\begin{array}{l}\text { SILVA, Silvina } \\
\text { Pimentel }\end{array}$ & $\begin{array}{l}\text { Histórias de Formação em Grupos de Iniciação Cientifica: } \\
\text { trajetórias da UECE e da UFC (1985 a 2005) }\end{array}$ & $\mathrm{D}$ & BDTD \\
\hline 2011 & $\begin{array}{l}\text { ULIANA, Edna } \\
\text { Regina }\end{array}$ & $\begin{array}{l}\text { Formação inicial e área de atuação profissional do curso de } \\
\text { licenciatura plena em Ciências Biológicas da Universidade } \\
\text { Federal de Mato Grosso de período de 2004-2009. }\end{array}$ & $M$ & CAPES \\
\hline 2012 & $\begin{array}{l}\text { BRACCINI, Marja } \\
\text { Leão }\end{array}$ & $\begin{array}{l}\text { A iniciação científica e o exercício da docência na } \\
\text { educação básica: ressignificações da experiência de } \\
\text { professores iniciantes }\end{array}$ & $M$ & BDTD \\
\hline 2012 & $\begin{array}{l}\text { COELHO FILHO, } \\
\text { Mateus de Souza }\end{array}$ & $\begin{array}{l}\text { A Iniciação Científica de Professores em Formação Inicial } \\
\text { do Curso de Pedagogia da Universidade do Estado Do } \\
\text { Amazonas, Polo Parintins-AM. }\end{array}$ & $M$ & CAPES \\
\hline 2013 & $\begin{array}{l}\text { SANTOS, Jaqueline } \\
\text { Correa dos }\end{array}$ & $\begin{array}{l}\text { Acesso e permanência no curso de Pedagogia da } \\
\text { Universidade Federal da Bahia: um estudo sobre as } \\
\text { estratégias dos estudantes oriundos das escolas públicas. }\end{array}$ & $M$ & CAPES \\
\hline 2015 & $\begin{array}{l}\text { VICENTE, Raniery } \\
\text { Guilherme José }\end{array}$ & $\begin{array}{l}\text { Trajetórias educacionais bem-sucedidas: o reverso da } \\
\text { evasão. }\end{array}$ & $M$ & BDTD \\
\hline 2016 & SOARES, Marisa & $\begin{array}{l}\text { A prática da pesquisa no ensino superior: a iniciação científica } \\
\text { como mediação da aprendizagem significativa. }\end{array}$ & $D$ & BDTD \\
\hline 2016 & $\begin{array}{l}\text { LEMOS, Nívea } \\
\text { Roberta Moraes } \\
\text { Barbosa } \\
\end{array}$ & $\begin{array}{l}\text { Relações entre o currículo vivido no curso de Pedagogia } \\
\text { e o processo de construção da identidade do professor. }\end{array}$ & $M$ & CAPES \\
\hline 2020 & $\begin{array}{l}\text { CALEFI, Roberta } \\
\text { Maura }\end{array}$ & $\begin{array}{l}\text { Iniciação científica na licenciatura em Química: relações } \\
\text { entre pesquisa, formação inicial e a área de educação } \\
\text { química }\end{array}$ & $\mathrm{D}$ & CAPES \\
\hline
\end{tabular}

Fonte: Elaborado pelos autores (2021).

Chama a atenção que, entre 100 trabalhos (teses, dissertações e artigos), apenas 11 sejam dedicados à temática da IC nos cursos de licenciatura. Os demais discutem aspectos relacionados às contribuições gerais da IC para os mais variados cursos; introdução à pesquisa e metodologia científica; apropriação da linguagem científica; autoria nos relatórios de IC; atividades práticas em laboratórios e outros contextos; fatores que influenciam no acesso às bolsas; a influência da IC para a pós-graduação; estudos de caso sobre os efeitos do PIBIC em instituições; análise sobre programas de IC criados por universidades; a IC no Ensino Médio, entre outras temáticas.

Outro destaque em relação às pesquisas é que nenhuma tese de doutorado é apresentada como continuação de pesquisa de mestrado. Além disso, por meio de 
leitura dos currículos dos autores na Plataforma Lattes do CNPq, apenas uma autora publicou os resultados de sua investigação de doutorado em formato de artigo científico (SOARES; SEVERINO, 2018). Cabe destacar, também, que as pesquisas foram desenvolvidas em instituições de diversos estados do país, como UNICAMP, UNIMEP e UNINOVE (São Paulo); UFSM e UNISINOS (Rio Grande do Sul); UFCE (Ceará); UFMT (Mato Grosso); UFAM (Amazonas); UFBA (Bahia); UnB (Distrito Federal); e UFPE (Pernambuco).

A leitura dos 11 trabalhos completos permitiu a identificação de núcleos de discussão que privilegiam aspectos relacionados às contribuições da IC nos cursos de licenciatura: a) para a formação acadêmica e científica dos bolsistas; b) como instrumento de permanência do ensino superior; c) para o exercício da docência.

\section{Contribuições para a formação acadêmica e científica dos bolsistas}

As pesquisas de Soares (2016) e Silva (2008) apontam aspectos mais gerais da formação de licenciandos, confirmando contribuições já destacadas nos estudos de Massi e Queiroz (2010), Pinho (2017), Soares e Severino (2018) e demais autores.

Soares (2016) buscou analisar quais contribuições as práticas de IC podem oferecer ao processo de ensino e aprendizagem entre alunos e orientadores dos cursos de Pedagogia. A autora aplicou questionários a professores orientadores, alunos e egressos de cursos de licenciaturas de Pedagogia de uma universidade particular do estado de São Paulo.

Do ponto de vista dos orientadores e dos alunos, a atividade de IC contribui para a aprendizagem de conhecimentos de metodologia científica e para a formação crítica dos alunos. Nesse sentido, a atividade de IC amplia a formação crítica dos graduandos e o contato com a pós-graduação (grupos de pesquisa, participação em eventos científicos, elaboração de artigos e pôsteres, apresentação de trabalhos, organização de eventos, elaboração e relatórios de pesquisa etc.) torna a aprendizagem mais complexa e desafiante Segundo o autor, a IC contribui, ainda, com a prática de leitura e intepretação sistemática de artigos e trabalhos acadêmicos, com o desenvolvimento de uma escrita própria, com a disciplina de cumprimento de prazos 
para devolutivas de resultados da pesquisa e com o desenvolvimento do trabalho de conclusão de curso.

Silva (2008) buscou compreender em que medida a participação em grupos de IC na Universidade constitui-se, para pedagogos e pedagogas que dela participam, em experiências formadoras para suas atividades profissionais. Inventariou o percurso de grupos de pesquisa da Universidade Estadual do Ceará - UECE e da Universidade Federal do Ceará - UFC no período de 1985 a 2005 por meio de narrativas de ex-bolsistas PIBIC e orientadores. Os resultados indicaram que o trabalho científico oferece um diferencial na formação dos estudantes na medida em que os afasta do senso comum e oferece a oportunidade de uma leitura mais rigorosa e objetiva da realidade. Afirma, ainda, que a participação em experiência de pesquisa como conteúdo de formação contribui para a elaboração do pensamento e no aprimoramento teórico, pois "influencia no modo como pensamos, decidimos ou fazemos as coisas" (SILVA, 2008, p. 186).

A experiência de pesquisa é muito importante, segundo a autora, especialmente porque a relação teoria e prática é incipiente no conjunto de ações desenvolvidas nas disciplinas do curso de Pedagogia.

A pesquisa de Uliana (2011), por sua vez, buscou analisar a formação inicial e atuação profissional de egressos do curso de Licenciatura em Ciências Biológicas (período de 2004 a 2009) da Universidade Federal de Mato Grosso - UFMT, campus Cuiabá, buscando estabelecer relações entre essas duas dimensões do processo de profissionalização. Discute o modelo da licenciatura construída a partir do bacharelado a partir do esquema “ $3+1$ ” — os três primeiros anos dedicados ao estudo de conhecimentos específicos e o último ao estudo das questões didático-pedagógicas, característica da racionalidade técnica - e a necessidade de se adotar um novo modelo de formação orientado pelo modelo da racionalidade prática e pela concepção de professor como um produtor de conhecimentos.

O aspecto mais relevante do curso, segundo os sujeitos, foi a formação para a pesquisa possibilitada por algumas disciplinas específicas e também pela IC. Não há referência às contribuições da IC para aspectos relacionados à formação de professores, mas ao desenvolvimento do gosto para a pesquisa e à produção e socialização de conhecimentos que contribuíram para a formação profissional de 
modo geral e preparação para a pós-graduação. Dos 58 estudantes egressos envolvidos no estudo, 78\% investiram em cursos de pós-graduação (62\% mestrado, 17\% doutorado), especialmente em cursos da área de Biologia.

Outra pesquisa que analisa as relações entre pesquisa e formação docente foi desenvolvida por Calefi (2020). A autora investiga os trabalhos de IC desenvolvidos por licenciandos em Química e apresentados nas reuniões científicas da Sociedade Brasileira de Química - SBQ (seção de "Ensino de Química”). Segundo a análise tecida, foi confirmada a hipótese de que "que os trabalhos de IC sejam representativos da produção científica da área de Educação Química e, por tal razão, possam possibilitar a inserção dos alunos de iniciação científica nesta área” (CALEFI, 2020, p. 17).

Ainda sobre a investigação de Calefi (2020), pode-se destacar que seus resultados informam o percentual de alunos que continuaram a desenvolver atividades de pesquisa: 75\% dos autores dos trabalhos de IC analisados ingressaram no mestrado. Isto denota que, assim como defende Pinho (2017), embora a IC também deva ter como fim a formação pedagógica do bolsista, a inserção na prática de pesquisa pode preparar e incentivar a entrada na pós-graduação.

Nessa perspectiva, podemos afirmar que os trabalhos analisados destacam que a experiência de IC pode contribuir com a formação acadêmica e científica dos licenciandos na medida em que favorece: a) a aprendizagem de conhecimentos de metodologia científica, leitura e intepretação sistemática de artigos e trabalhos acadêmicos; b) a elaboração do pensamento, da escrita e aprimoramento teórico; c) a ampliação da formação crítica dos alunos, afastando-os do senso comum e oferecendo a oportunidade de uma leitura mais rigorosa e objetiva da realidade; d) a inserção dos licenciandos na área de conhecimento de seu curso por meio da produção e socialização de conhecimentos; e) a preparação para a entrada na pós-graduação.

Estas contribuições confirmam outras análises que argumentam que a possibilidade de experienciar a prática de pesquisa na IC pode introduzir ao repertório do bolsista conhecimentos próprios do "fazer" pesquisa que potencializam a construção de indagações e hipóteses na tentativa de se compreender a realidade (BRIDI, 2010; MASSI; QUEIROZ, 2010; SOARES; SEVERINO, 2018). 


\section{Contribuições da IC como instrumento de permanência no ensino superior}

As pesquisas de Santos, J. (2013) e Vicente (2015) discutem as contribuições da IC de um ponto de vista social, valorizando as possibilidades dela de colaborar com o ingresso e permanência dos estudantes no ensino superior.

Santos, J. (2013) investigou as estratégias implementadas pelos alunos oriundos das escolas públicas para acessarem e permanecerem no curso de Pedagogia da Universidade Federal da Bahia - UFBA. Considerando a origem social dos estudantes a autora identificou que o PIBIC, assim como o Programa Institucional de Bolsa de Iniciação à Docência (Pibid) e auxílios da Pró-reitoria de Ações Afirmativas e Assistência Estudantil (PROAE) da universidade são formas de apoio financeiro a que os alunos recorrem para permanecer na universidade.

Seu estudo destaca a "importância do papel da instituição na garantia das ações necessárias à inclusão de forma plena desse sujeito na Universidade, permitindo não só o acesso, mas a permanência qualificada no curso" (SANTOS, J., 2013, p. 8) e reforça que, muito embora os objetivos do PIBIC estejam relacionados à formação do pesquisador, o Programa aparece como uma das mais importantes estratégias para a permanência na Universidade.

Segundo os dados da pesquisa, o curso de Pedagogia é um curso feminino e as alunas frequentaram, na sua maioria, escolas públicas. São oriundas de famílias de baixa renda e compõem o grupo de alunos pardos e pretos. A autora compreende que, neste contexto, os dados levantados sugerem que a entrada no curso de Pedagogia é uma das portas de entrada desse segmento da população que ainda é minoria nas universidades públicas federais brasileiras (SANTOS, J., 2013).

A dissertação de Vicente (2015) se propôs a compreender as trajetórias de sucesso de estudantes de camadas populares em cursos de licenciaturas, identificar quais fatores/serviços têm proporcionado condições de permanência no Instituto Federal de Educação, Ciência e Tecnologia do Norte de Minas Gerais - IFNMG, campus Januária, bem como identificar os fatores e programas institucionais que podem ser facilitadores ou dificultadores da permanência do aluno nesses cursos. 
Dada a predominância de estudantes de baixa renda nos cursos de licenciatura do Instituto, o autor defende que a ampliação da assistência estudantil (auxílios financeiros e a oferta de moradia gratuita) e de programas de bolsas (PIBIC, Pibid e Pibex) contribuem para a permanência de mais alunos nos cursos de licenciatura da instituição, evitando a evasão.

Cabe ressaltar que não somente alunos de cursos de licenciaturas têm sua permanência na Universidade garantida por meio de bolsas e outros auxílios. Em consonância com os resultados dos dois trabalhos anteriores, Batista (2016) examinou as trajetórias de sucesso escolar de estudantes de cursos considerados de alto prestígio social (Direito, Medicina, Odontologia, Engenharia Elétrica, Engenharia Civil e Ciências da Computação) na Universidade Federal da Paraíba - UFPB. Para compreender os processos que favorecem o ingresso e a permanência desses jovens foram aplicados questionários a 60 estudantes oriundos de escolas públicas e bolsistas PIBIC. Muito embora as trajetórias sejam muito singulares e o sucesso acadêmico seja afetado por relações de interdependência entre família, escola, relação com o saber e desejo de mobilidade social, a pesquisa confirmou a necessidade de ampliação dos programas de IC e assistência estudantil para estudantes de baixa renda como condição para obtenção de sucesso na graduação.

O PIBIC/CNPq é citado como uma importante ferramenta de incentivo à permanência na graduação, pois além de conferir uma titulação e distinção no seu currículo, também serve de base para outros "projetos de vida". Projetos considerados ousados e promissores como: ampliar a formação acadêmica com a pós-graduação (mestrado e doutorado) e atuar na carreira acadêmica em que se formaram ou virem a atuar como professores universitários (BATISTA, 2016, p. 173-174).

Ante o exposto, é possível destacar que, além das contribuições anteriormente discutidas da IC para a formação acadêmica e científica dos licenciandos, há necessidade de reconhecê-la em sua função social na medida em que se caracteriza, conforme descrito pelas investigações acima, como instrumento de permanência de alunos em situação social e econômica mais vulnerável no ensino superior.

\section{Contribuições para o Exercício da Docência}

Os trabalhos de pesquisa de Melo (2003), Kirsch (2007), Braccini (2012), Coelho Filho (2012) e Lemos (2016) oferecem um panorama de contribuições da IC 
nos cursos de licenciatura diretamente relacionado ao exercício da docência na educação básica. Há que se considerar, no entanto, que os aspectos destacados têm relação com as contribuições para a formação acadêmica e científica dos licenciandos de modo geral.

A pesquisa de Kirsch (2007) objetivou compreender as contribuições da IC no processo formativo docente proporcionado às egressas do curso de Pedagogia da Universidade Federal de Santa Maria - UFSM que tinham sido bolsistas durante o curso. Discute o papel da IC na formação inicial partindo do pressuposto de que a IC contribui para o desenvolvimento do pensamento crítico e reflexivo dos alunos de graduação e futuros professores. As entrevistas com 10 egressas permitiram identificar que a IC foi motivada pela necessidade de ampliar conhecimentos teóricos e práticos e favoreceu, ao longo de seu desenvolvimento, um estudo aprofundado que ampliou seus referenciais de modo que, posteriormente, sentiram-se mais seguras nas práticas pedagógicas, sendo capazes de fundamentar seus fazeres e saberes.

Além desses aspectos, a atividade de pesquisa mobilizou a necessidade de formação continuada como parte integrante do desenvolvimento profissional docente, estimulando as ex-bolsistas a continuarem seus estudos na pós-graduação.

É importante destacar que a IC oportuniza, ainda, segundo a autora, o envolvimento do bolsista num processo de trabalho coletivo, pois o desenvolvimento de um projeto de pesquisa não envolve apenas o bolsista e professor-orientador, mas também outros sujeitos num ambiente de interação entre pares.

Nesse sentido, a autora destaca que

a iniciação científica é extremamente importante na formação inicial dos professores, pois é um espaço de trabalho individual e coletivo, que exige estudo aprofundado de aportes teóricos que possam sustentar a pesquisa em desenvolvimento, levando as acadêmicas bolsistas de projetos à reconstrução e também à produção de conhecimentos, estimulando o pensar sobre situações acadêmicas e escolares, através de um processo reflexivo, bem como instiga as bolsistas de iniciação científica a prosseguirem na formação, a partir do desenvolvimento de projetos de pesquisa próprios. Portanto, almejamos que a experiência com pesquisa, nos processos formativos para a docência, possa ser encarada como um contínuo, que não se esgote com o recebimento do diploma, mas acompanhe as acadêmicas egressas durante toda sua trajetória profissional (KIRSCH, 2007, p. 95).

Braccini (2012) investigou as contribuições da IC na perspectiva de egressas dos cursos de licenciatura (História, Biologia, Física e Matemática) da Universidade 
do Vale do Rio dos Sinos - Unisinos e também observou que a experiência com a pesquisa pode ajudar na adaptação, enfrentamento e reconhecimento dos atravessamentos que envolvem o trabalho na escola básica. Nas entrevistas, as ex-bolsistas e então professoras apontaram "que fazer pesquisa é importante como princípio da dúvida e da intenção de construir com os alunos o conhecimento" (BRACCINI, 2012, p. 80) e que a experiência na IC as ajudou a se afastarem da concepção de ensino como transferência de conhecimento, aproximando-as do modelo de ensinar com pesquisa.

Os resultados da investigação de Braccini (2012) lhes permitiu compreender que os professores com experiência de IC na graduação passaram a "gostar de fazer pesquisa" e, consequentemente, começaram a trabalhar com pesquisas em sala de aula com seus alunos justificando a importância de favorecer o desenvolvimento da autonomia e a construção de conhecimento. Alguns deles afirmaram a intencionalidade de trabalhar com pesquisa como forma de ensinar os alunos a duvidarem do conhecimento que está posto e que precisa ser construído. Valorizaram, ainda, a autonomia e a tomada de decisões, as habilidades de análise e síntese, o desenvolvimento da oralidade na defesa das ideias e o exercício do trabalho coletivo. Chamaram a atenção, contudo, para a importância de condições objetivas de trabalho que permitam o desenvolvimento de um ensino com pesquisa.

A investigação de Lemos (2016) tratou das articulações entre o curso de Pedagogia da Universidade Federal de Pernambuco - UFPE e a dinâmica de invenção de si como professor e objetivou identificar no discurso de estudantes como os componentes curriculares do curso de Pedagogia e as atividades complementares se relacionavam com o processo de construção da identidade.

Especificamente com relação ao PIBIC emergiu

o sentido de que a pesquisa quando articulada à prática profissional, colabora na superação de uma educação pautada no ensino como transmissão e da aprendizagem como memorização, neste caso, o sujeito pode assumir uma posição ativa e propositiva no processo de produção de saberes e constrói a si mesmo com base na reflexão, investigação e autonomia (LEMOS, 2016, p. 8).

Também problematizando a IC no curso de Pedagogia, Coelho Filho (2012) desenvolveu uma investigação que analisou as experiências de professores em 
formação inicial na Universidade do Estado do Amazonas - UEA, campus Parintins, que fizeram IC. Em seus resultados o autor destaca que a inserção da pesquisa na formação das alunas da Pedagogia proporcionou o desenvolvimento reflexivo e crítico dos sujeitos, ampliando suas visões de ciência e da atividade docente como espaço de produção de saberes. No itinerário formativo das bolsistas a pesquisa se apresenta como instrumento que possibilita a leitura da realidade científica, profissional e social.

Ainda sobre as contribuições da IC para a atuação docente, destacamos o trabalho de Melo (2003). Nele, o autor investiga os saberes produzidos por uma licencianda em matemática acerca do ensino de álgebra elementar durante sua trajetória de formação no curso concomitante ao desenvolvimento de um projeto de IC. Nos resultados analisados são destacadas as ressignificações da aluna em relação à prática de ensino de matemática na escola básica e à formação inicial de professores. No que tange à articulação da IC ao processo formativo, o autor sinaliza que:

por intermédio da pesquisa, os profissionais terão ampliadas as suas possibilidades para o exercício das funções docentes, e no caso do ensino - atividade principal - desenvolver um trabalho melhor, pois ampliará a sua visão acerca da prática desenvolvida situando o conteúdo específico com o qual manifesta tensões e conflitos no processo complexo de ensinar para estudantes do Ensino Fundamental e Médio. Trata-se ainda de integrar no domínio da formação com continuidade na prática a relação pesquisa-ensino o que contribuirá para a formação e relação com os saberes nestes níveis de ensino (MELO, 2003, p. 61).

Lüdke (2012), em estudo anterior que discute o papel da pesquisa na formação e na prática dos professores, já evidenciava que os professores de educação básica que tiveram contato com IC reconheceram as contribuições para o domínio dos estudos de seu campo.

Assim, na esfera da educação, um campo de composição plural, isso pode ocorrer com frequência, pois os estudantes podem adquirir conhecimentos de diferentes campos do saber (filosofia, sociologia, psicologia etc.) como, também, de suas perspectivas teóricas e metodológicas próprias. Tal abrangência de saberes e possibilidade de articulação entre teoria e prática durante a formação corrobora para o desenvolvimento profissional docente defendido por Soares e Cunha (2010) na medida em que a integração entre conhecimentos práticos e teóricos proporcionados pela IC coloca a formação numa dimensão pessoal de desenvolvimento humano e global: 


\begin{abstract}
A formação profissional do professor implica concebê-lo como ator/autor da sua trajetória de vida e emergente da teia econômica, social e cultural em que está inserido e como profissional que busca a formação, reconhece suas necessidades e a do contexto em que atua, se compromete reflexivamente na transformação das práticas e na afirmação da profissionalidade docente (SOARES; CUNHA, 2010, p. 32).
\end{abstract}

As contribuições da IC ao exercício da docência são evidenciadas, portanto, pelo desenvolvimento do pensamento crítico e reflexivo que favorece a autonomia e possibilita a leitura da realidade científica, profissional e social; a ampliação dos conhecimentos teóricos e práticos necessários para a fundamentação da ação docente; o reconhecimento da atividade docente como espaço de produção de saberes; a compreensão da relação pesquisa-ensino no contexto do trabalho coletivo; e a valorização da formação continuada para o desenvolvimento profissional docente.

A experiência com a prática de pesquisa permite que os licenciandos, quando professores atuantes na sala de aula, reconheçam os condicionantes do trabalho na escola; ajudem seus alunos a questionar e a duvidar de respostas simplistas, perguntando pelo sentido dos conhecimentos; incorporem um modelo de ensinar com pesquisa, ou seja, avesso à concepção de ensino como transmissão de conhecimento e sensível aos processos de reflexão e investigação.

Todos esses aspectos não podem ser negligenciados e são coerentes com as proposições dos educadores comprometidos com uma concepção de formação reflexiva e crítica necessária à produção de conhecimentos baseados nas práticas dos professores (COCHRAN-SMITH; LYTLE, 1999, 2009; ZEICHNER, 1998, 2010; NÓVOA, 2017).

A pesquisa de professores da educação básica, em diálogo com o conhecimento acadêmico da universidade, pode fornecer elementos para a compreensão da complexidade das práticas docentes (ZEICHNER, 2010). Através da prática da investigação, segundo Cochran-Smith e Lytle (1999), os professores, ao longo de sua vida profissional, problematizam seu próprio conhecimento, bem como o conhecimento e a prática de outros, colocando-se em uma relação diferente com seu universo de referências.

Partindo dos mesmos princípios, Nóvoa (2017) defende uma formação influenciada pela dimensão profissional em que a realidade escolar se constitua como 
objeto de reflexão e pesquisa dos professores, isto é, como processo de análise sistemática do trabalho em colaboração com os pares da escola.

\section{Considerações finais}

As pesquisas sobre as contribuições da IC para formação inicial de professores, temática ainda não explorada pela literatura, reforçam aspectos de formação geral como a aprendizagem de conhecimentos de metodologia científica, contato com a produção acadêmica da área de conhecimento da licenciatura, aprofundamento teórico, formação crítica dos alunos e preparação para a entrada na pós-graduação. Esses resultados são comuns a investigações que se debruçaram sobre outros cursos de graduação, como Oliveira (2013) e Cruz (2019), entre outros.

O inventário de trabalhos, no entanto, evidencia contribuições específicas da IC para o exercício da docência e, nesse sentido, aponta reflexões importantes para coordenadores e professores de curso de licenciatura que têm a responsabilidade de articular ensino e a pesquisa e criar oportunidades de incentivar a investigação como postura entre os futuros professores.

A pesquisa desenvolvida na IC, integrada a outras dinâmicas formativas que privilegiam a pesquisa, pode ser considerada como uma experiência que forma um determinado olhar e uma postura investigativa diante da complexidade da prática pedagógica que desloca o professor de "consumidor" de ideias e teorias para um lugar de "produtor" de conhecimentos da prática do mesmo modo que deixa de se reconhecer como "transmissor" de conhecimentos e reconhece seus alunos como "construtores" de conhecimentos.

A contribuição da IC para a permanência dos estudantes é um aspecto que merece atenção e desafia a reflexão sobre a distribuição de bolsas entre as instituições e o número disponibilizado para os estudantes de graduação. Pinho (2017) ressalta que o número de bolsas PIBIC é insuficiente para atender à demanda qualificada nas instituições. Sendo restrita a poucos alunos e aparentemente privilegiando os alunos com melhor desempenho acadêmico, acaba por se caracterizar como uma atividade muito seletiva. 
Bridi (2010) e Pires (2008) problematizam entraves à consolidação da IC tanto em termos de acesso à pesquisa ou caminho de continuidade aos estudos. Bridi (2010, p. 108) ressalta como fatores limitantes aos benefícios da IC, por exemplo, "a falta de tempo dos professores e dos alunos por excesso de atividades, a falta de valorização da atividade de orientação de graduandos, laboratórios ultrapassados, falta de estrutura”. A pesquisa de Pires (2008) destaca, ainda, que a ênfase na formação de cientistas não pode ser único objetivo da IC, afinal, as contribuições para formação humana, social e cultural não podem ser secundarizadas.

Santos, S. (2013) chama a atenção para outro aspecto: a distorção dos objetivos da IC para a formação dos alunos na graduação na medida em que ela é vista apenas como oportunidade de enriquecimento do Currículo Lattes considerando-se a concorrência no mercado de trabalho, incluindo o acesso às atividades acadêmicas na pós-graduação.

Frente a todos os argumentos e resultados de pesquisas é preciso destacar a relevância da IC para a formação dos estudantes de graduação e, de modo particular, para os licenciandos. A pesquisa na licenciatura deve ser considerada como experiência formativa na medida em que admite os conhecimentos da sala de aula e os saberes dos professores como problemáticos e o percurso investigativo como possibilidade de elaboração e reelaboração desses conhecimentos e saberes.

Dada a escassez de trabalhos sobre a temática faz-se necessário dar mais atenção à discussão da pesquisa como princípio formativo no contexto da IC e incentivar trabalhos que documentem as experiências de bolsistas e egressos na perspectiva da pesquisa narrativa e (auto)biográfica de modo que possamos conhecer melhor os atravessamentos da relação pesquisa-docência.

\section{Referências}

ANDRÉ, M. E. D. A. de. A complexa relação entre o professor e a pesquisa. In: ANDRÉ, M. E. D. A. de (Org.). O papel da pesquisa na formação e na prática dos professores. Campinas: Papirus, 2012.

BATISTA, N. M. L. Trajetórias de sucesso escolar dos jovens oriundos de escolas públicas no ensino superior. 2016. 187 f. Orientador: Emília Maria da Trindade Prestes. Dissertação (Mestrado em Educação Popular) - Centro de Educação, Universidade Federal da Paraíba, João Pessoa, 2016. 
BRACCINI, M. L. A iniciação cientifica e o exercício da docência na educaşão básica: ressignificações da experiência de professores iniciantes. 2012. 93p. Orientador: Maria Isabel da Cunha. Dissertação (Mestrado em Educação) - Programa de Pós-Graduação em Educação, Universidade do Vale do Rio dos Sinos, São Leopoldo, RS, 2012.

BRASIL. Ministério da Ciência e Tecnologia. Conselho Nacional de Desenvolvimento Científico e Tecnológico. RN-017/2006. Estabelece as normas gerais e específicas para as modalidades de bolsas por quota no País. 2006. Disponível em: http:/ /www.cnpq.br/view//journal_content/56_INSTANCE_0oED/10157/100352. Acesso em: 03 maio. 2018.

BRIDI, J. C. A. Atividade de pesquisa: contribuição da Iniciação Científica na formação geral do estudante universitário. Olhar de Professor, Ponta Grossa, v. 13, p. 349-360, 2010. Disponível em: https://www.revistas2.uepg.br/index.php/olhardeprofessor/article/view/2521. Acesso em: 19 jan. 2020.

CALEFI, R. Iniciação científica na licenciatura em Química: relações entre pesquisa, formação inicial e a área de Educação Química. 2020. 120f. Orientador: Thiago Borges de Aguiar. Tese (Doutorado em educação) - Programa de Pós-Graduação em Educação, Universidade Metodista de Piracicaba, Piracicaba, 2020.

COCHRAN-SMITH, M.; LYTLE, S. Relationships of knowledge and practice: teacher learning in communities. Review of Research in Education, n. 24, 1999. Disponível em: https://www.jstor.org/stable/1167272?seq=1 Acesso em: 19 dez. 2019.

COCHRAN-SMITH, M; LYTLE, S. Inquiry as stance: ways forward. In: COCHRANSMITH, M.; LYTLE, S. Inquiry as stance: practitioner research for the next generation. New York: Teachers College Press, 2009.

COELHO FILHO, M. de S. A Iniciação Científica de Professores em Formação Inicial do Curso de Pedagogia da Universidade do Estado do Amazonas, Polo Parintins-AM. 2012. 91 f. Orientador: Amarildo Menezes Gonzaga. Dissertação (Mestrado em Educação em Ciências na Amazônia) — Universidade do Estado do Amazonas, Parintins, 2012.

CONSELHO NACIONAL DE DESENVOLVIMENTO CIENTÍFICO E TECNOLÓGICO CNPQ. Mapa de Imvestimentos. 2019a. Disponivel em http://cnpq.br/mapa-de-investimentosnovo?p_auth=MepSzB0w\&p_p_id=mapabeneficiariosportlet_WAR_mapabeneficiariosportlet_INS TANCE_kvV2\&p_p_lifecycle=1\&p_p_state=normal\&p_p_mode=view\&p_p_col_id=column1\&p_p_col_count=1\&_mapabeneficiariosportlet_WAR_mapabeneficiariosportlet_INSTANCE_kv V2_javax.portlet.action=enviarDados\&cod_prog_ext= Acesso em: 24 fev. 2020.

CONSELHO NACIONAL DE DESENVOLVIMENTO CIENTÍFICO E TECNOLÓGICO (CNPQ). Séries Históricas até 2015. Bolsas no país: número de bolsas-ano segundo modalidades. 2019b. Disponível em: http://www.cnpq.br/web/guest/serieshistoricas/. Acesso em: 24 fev. 2020.

CUNHA, M I. da. A docência como ação complexa: o papel da didática na formação de professores. In: ROMANOWSKI, J. P. et al. (Org.). Conbecimento local e conhecimento universal: pesquisa, didática e ação docente. Curitiba: Universitária Champagnat, 2004.

CUNHA, M I. da. Verbetes: formação inicial e formação continuada. In: MOROSINI, M. C. (Org.). Enciclopédia de Pedagogia Universitária. Brasília: MEC/INEP, 2006. 
CRUZ, T. R. do N. Os primeiros passos na aventura de fazer ciência: a iniciação científica como espaço de formação em Serviço Social. 2019. 204p. Orientador: Roberta Ferreira Coelho de Andrade. Dissertação (Mestrado em Serviço Social e Sustentabilidade na Amazônia) Universidade Federal do Amazonas, Manaus, 2019.

FERREIRA, N. S. de A. As pesquisas denominadas "estado da arte". Educação e Sociedade, Campinas, v. 23, n. 79, p. 257-272, ago. 2002. Disponível em: http://www.scielo.br/pdf/es/v23n79/10857.pdf Acesso em: 09 jan. 2020.

GATTI, B. A; BARRETTO, E. S. de S.; ANDRÉ, M. E. D. A. de. Políticas de formação inicial de professores. In: GATTI, B. A; BARRETTO, E. S. de S.; ANDRÉ, M. E. D. A. de. Políticas docentes no Brasil: um estado da arte. Brasília: UNESCO, 2011.

GATTI, B. A.; NUNES, M. M. R. (orgs.). Formação de professores para o ensino fundamental: estudo de currículos das licenciaturas em pedagogia, língua portuguesa, matemática e ciências biológicas. São Paulo: FCC/DPE, 2009.

INSTITUTO NACIONAL DE ESTUDOS E PESQUISAS EDUCACIONAIS ANÍSIO TEIXEIRA. Sinopse Estatística da Educaşão Superior 2018. Brasília: Inep, 2019. Disponível em: http://portal.inep.gov.br/web/guest/sinopses-estatisticas-da-educacao-superior. Acesso em: 12 mar. 2020.

KIRSCH, D. B. A iniciação cientifica na formação inicial de professores: repercussões no processo formativo de egressas do curso de Pedagogia. 2007. 111p. Orientador: Doris Pires Vargas Bolzan. Dissertação (Mestrado em Educação) - Centro de Educação, Universidade Federal de Santa Maria, Santa Maria, RS, 2007.

LEMOS, N. R. M. B. Relações entre o currículo vivido no curso de Pedagogia e o processo de construção da identidade do professor. 2016. 95p. Orientador: Lucinalva Andrade Ataíde de Almeida. Dissertação (Mestrado em Educação Contemporânea) - Centro Acadêmico do Agreste, Universidade Federal de Pernambuco, Caruaru, 2016.

LÜDKE, M. Pesquisa, formação e prática docente. In: ANDRÉ, M. (Org.) O papel da pesquisa na formação e na prática dos professores. Campinas: Papirus, 2012.

MASSI, L.; QUEIROZ, S. L. Estudos sobre iniciação científica no Brasil: uma revisão. Cadernos de Pesquisa, São Paulo, v. 40, n. 139, p.173-197, jan./abr. 2010. Disponível em: http://www.scielo.br/pdf/cp/v40n139/v40n139a09.pdf Acesso em: 16 jan. 2020.

MELO, G. F. A. de. A formação inicial e a iniciação científica: investigar e produzir saberes docentes no ensino de álgebra elementar. 2003. 241 p. Orientador: Anna Regina Lanner de Moura. Tese (Doutorado em Educação) - Universidade Estadual de Campinas, Campinas, 2003.

NÓVOA, A. Firmar a posição como professor, afirmar a profissão docente. Cadernos de Pesquisa, São Paulo, v. 47, n. 166, p. 1106-1133, out./dez. 2017. Disponível em: http://www.scielo.br/pdf/cp/v47n166/1980-5314-cp-47-166-1106.pdf Acesso em: 20 jan. 2020.

OLIVEIRA, A. M. de. Contribuições do Programa Institucional de Bolsas de Iniciação Científica (PIBIC) para a formação do aluno de Psicologia. 2013. 101p. Orientador: Oswaldo Hajime Yamamoto. Dissertação (Mestrado em Psicologia, Sociedade e Qualidade de Vida) — Universidade Federal do Rio Grande do Norte, Natal, 2013. 
PINHO, M. J. de. Ciência e ensino: contribuições da iniciação científica na educação superior. Avaliação, Campinas; Sorocaba, v. 22, n. 3, p. 658-675, nov. 2017. Disponível em: http://www.scielo.br/pdf/aval/v22n3/1982-5765-aval-22-03-00658.pdf Acesso em: 09 jan. 2020.

PIRES, R. C. M. A formação inicial do professor pesquisador universitário do Programa Institucional de Bolsas de Iniciação Cientifica - PIBIC/CNPq e a prática profissional de seus egressos: um estudo de caso da Universidade do Estado da Bahia. 2008. 356p. Orientador: Denise Balarine Cavalheiro Leite. Tese (Doutorado em Educação) - Faculdade de Educação, Universidade Federal do Rio Grande do Sul, Porto Alegre, 2008.

SANTOS, J. C. dos. Acesso e permanência no curso de Pedagogia da Universidade Federal da Babia: um estudo sobre as estratégias dos estudantes oriundos das escolas públicas. 2013. 140p. Orientador: Rosilda Arruda Ferreira. Dissertação (Mestrado em Educação) — Faculdade de Educação, Universidade Federal da Bahia, Salvador, 2013.

SANTOS, S. A. do. Mudanças na graduação na universidade pública: a nova prática da Iniciação Científica. 2013. 126p. Orientador: João dos Reis Silva Júnior. Tese (Doutorado em Educação) - Centro de Educação e Ciências Humanas, Universidade Federal de São Carlos, São Carlos, 2013.

SILVA, S. P. Histórias de Formação em Grupos de Iniciação Cientifica: trajetórias da UECE e da UFC (1985 a 2005). 2008. 212p. Orientador: Ercília Maria Braga de Olinda. Tese (Doutorado em Educação) - Faculdade de Educação, Universidade Federal do Ceará, Fortaleza, 2008.

SOARES, M. Alfabetização no Brasil: o estado do conhecimento. Brasília: INEP/MEC, 1989.

SOARES, M. A prática da pesquisa no ensino superior: a iniciação científica como mediação da aprendizagem significativa. 2016. 114 f. Tese (Doutorado em Educação) - Programa de Pós-Graduação em Educação, Universidade Nove de Julho, São Paulo, 2016.

SOARES, M.; SEVERINO, A. J. A prática da pesquisa no ensino superior: conhecimento pertencente na formação humana. Avaliação, São Paulo, v. 23, n. 2, p. 372-390, 2018. Disponível em: http://www.scielo.br/pdf/aval/v23n2/1982-5765-aval-23-02-372.pdf Acesso em: 12 fev. 2020.

SOARES, S. R.; CUNHA, M. I. da. Formação do professor: a docência universitária em busca de legitimidade. Salvador: EDUFBA, 2010.

ULIANA, E. R. Formação inicial e área de atuação profissional do curso de licenciatura plena em Ciências Biológicas da Universidade Federal de Mato Grosso de período de 2004-2009. 2011. 165p. Orientador: Tânia Maria de Lima Beraldo. Dissertação (Mestrado em Educação) — Instituto de Educação, Universidade Federal de Mato Grosso, Cuiabá, 2011.

VICENTE, R. G. J. Trajetórias educacionais bem-sucedidas: o reverso da evasão. 2015. 127p. Orientador: Olgamir Francisco de Carvalho. Dissertação (Mestrado Profissional em Educação) — Faculdade de Educação, Universidade de Brasília, Brasília, 2015.

ZEICHNER, K. Repensando as conexões entre a formação na universidade e as experiências de campo na formação de professores em faculdades e universidades. Educação, Santa Maria, v. 35, n. 3, p. 479-504, set./dez. 2010. Disponível em: https://periodicos.ufsm.br/reveducacao/article/view/2357 Acesso em: 12 jan. 2020. 
ZEICHNER, K. Para além da divisão entre professor-pesquisador e pesquisador acadêmico In: GERALDI, C. M.; FIORENTINI, D.; PEREIRA, E. M. (orgs.). Cartografia do trabalho docente: professor(a)-pesquisador(a). Campinas: Mercado de Letras; ABL, 1998. p. 207-236.

RECEBIDO: $11 / 02 / 2021$

RECEIVED: 02/11/2021

APROVADO: 03/06/2021

APPROVED: 06/03/2021

RECIBIDO: $11 / 02 / 2021$

APROBADO: 03/06/2021 